\title{
Fast Prediction of Differential Mode Noise Input Filter Requirements for FLyback and Boost Unity Power Factor Converters
}

\author{
Andersen, Michael Andreas E.
}

Published in:

Proceedings of the 1997 IEEE 12th Applied Power Electronics Conference

Link to article, DOI:

10.1109/APEC.1997.581458

Publication date:

1997

Document Version

Publisher's PDF, also known as Version of record

Link back to DTU Orbit

Citation (APA):

Andersen, M. A. E. (1997). Fast Prediction of Differential Mode Noise Input Filter Requirements for FLyback and Boost Unity Power Factor Converters. In Proceedings of the 1997 IEEE 12th Applied Power Electronics Conference (Vol. 1, pp. 230-234). IEEE. https://doi.org/10.1109/APEC.1997.581458

\section{General rights}

Copyright and moral rights for the publications made accessible in the public portal are retained by the authors and/or other copyright owners and it is a condition of accessing publications that users recognise and abide by the legal requirements associated with these rights.

- Users may download and print one copy of any publication from the public portal for the purpose of private study or research.

- You may not further distribute the material or use it for any profit-making activity or commercial gain

- You may freely distribute the URL identifying the publication in the public portal 


\title{
Fast Prediction of Differential Mode Noise Input Filter Requirements for Flyback and Boost Unity Power Factor Converters.
}

\author{
Michael A. E. Andersen \\ Institute of Automation, Technical University of Denmark \\ Building 327, DTU, DK-2800 Lyngby, DENMARK. \\ Phone: (+45) 45253604, fax:(+45) 45879572, e-mail: ma@iau.dtu.dk
}

\begin{abstract}
Two new and simple methods to make predictions of the differential mode input filter requirements are presented, one for flyback and one for boost unity power factor converters. They have been verified by measurements. They give the designer ability to predict the DM input noise filter requirements early in the design.
\end{abstract}

\section{INTRODUCTION}

Today unity power factor regulation becomes more and more important. There is a need for being able to design the input noise filters early in the design phase of unity power factor converters (PFC). Two new methods to make prediction of the differential mode input filter requirements are presented, one for flyback and one for boost unity power factor converters. It is shown that these two methods match with very complex and time consuming simulations and that they match with measurements too. This gives the designer a fast method to predict the differential mode input noise filter requirements, a tool for designing minimum size input filters.

\section{NOISE MEASUREMENTS - A BRIEF RESUME.}

Noise from converters are measured $[1,2]$ according to [6] as a voltage in $\mathrm{dBuV}$ across a LISN (Line Impedance Stabilisation Network) impedance. It is a quasi-peak measurement, i.e. the receiver is bandwidth limited to $9 \mathrm{kHz}$ and it has an electrical charge time constant of lms, an electrical discharge time constant $160 \mathrm{~ms}$, and a mechanical time constant of $160 \mathrm{~ms}$. Form this it can be seen that a pure peak measurement must be a worst case (but quite close) compared to a quasi-peak measurement.

\section{PFC FLYBACK OPERATING IN DISCONTINUOUS CONDUCTION MODE WITH A FIXED ON-TIME.}

The flyback converter is very popular because it is easy to have galvanic isolation and a simple control gives high power factor. When operating a flyback converter in discontinuous conduction mode with a fixed on-time the average of the input current becomes proportional to the input voltage. This way high power factor is achieved, and then the output voltage only has to control the on-time.

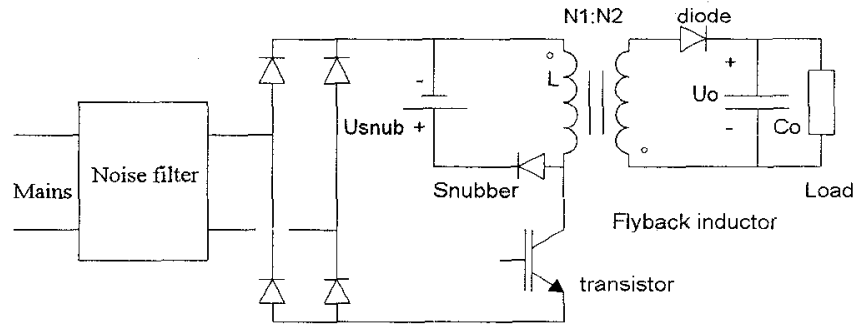

Fig. 1: Flyback converter for PFC with input noise filter.

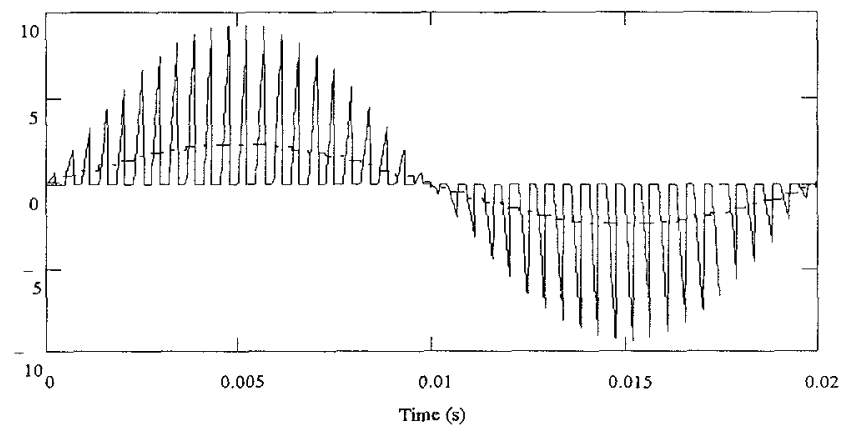

Fig. 2. Mains current and flyback input current (in A) (with a low ratio between switching and mains frequency to get a nice drawing)

For a flyback converter in discontinuous conduction mode with a fixed on-time it can be shown that:

$\widehat{\mathrm{I}}_{\mathrm{L}}=2 \cdot \sqrt{\frac{\mathrm{P} \cdot \mathrm{T}}{\mathrm{L}}} \quad \mathrm{t}_{\text {on }}=\frac{2 \cdot \sqrt{\mathrm{P} \cdot \mathrm{L} \cdot \mathrm{T}}}{\widehat{\mathrm{U}}_{\text {mains }}} \quad \mathrm{P}=\frac{\widehat{\mathrm{U}}_{\text {mains }} \cdot \hat{\mathrm{I}}_{\text {mains }}}{2}$

where $\hat{I}_{L}$ is the peak inductor current, $T$ is the switching frequency period, $P$ is the power, $L$ is the inductance, $t_{\text {on }}$ is the on-time, and $\hat{\mathrm{U}}_{\text {mains }}$ and $\hat{\mathrm{I}}_{\text {mains }}$ respectively are the mains peak voltage and current.

\section{A. PFC flyback input current FFT spectrum.}

A $200 \mathrm{~W} 230 \mathrm{~V}$ AC PFC flyback converter with a switching frequency of $62.5 \mathrm{kHz}$ and $\mathrm{L}=48 \mathrm{uH}$ has been simulated. The flyback converter has a very high ripple current on the input as shown on figure 2. By applying FFT on the ripple current the spectrum on figure 3 can be computed.

This FFT calculation requires a lot of points and takes a lot of time to get an exact result so a faster method is needed. 


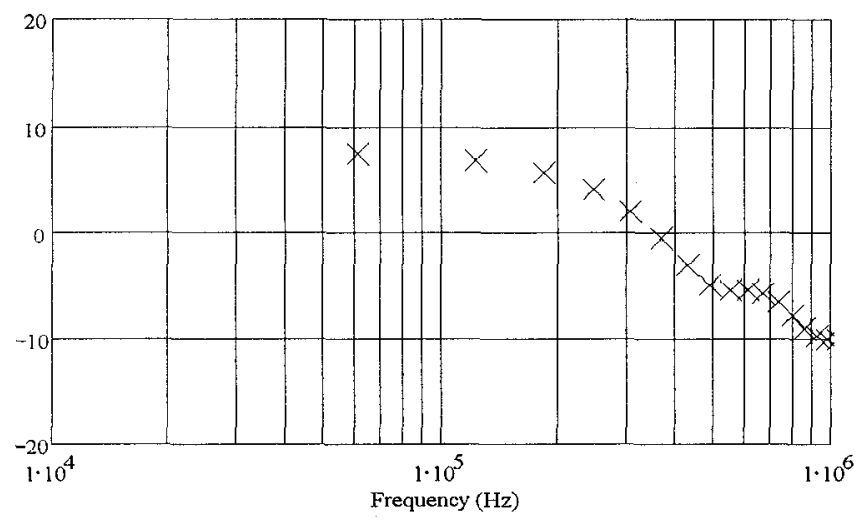

Fig. 3. Frequency spectrum of flyback input current (in $\mathrm{dB}$ Ampere peak). Each of the points are harmonics of the switching frequency $f_{s}=62.5 \mathrm{kHz}$.

\section{B. Prediction of PFC flyback input current spectrum.}

A single switching period of the flyback input current is shown on figure 4 .

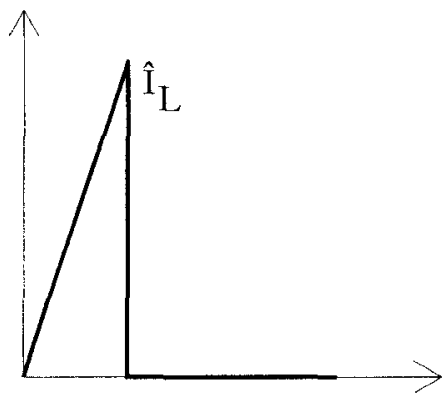

$0 \quad t_{\text {an }} \quad \mathrm{T}$

Fig. 4: Biscontinuous saw-tooth wave-form. I.e. a single switching period of the flyback input current.

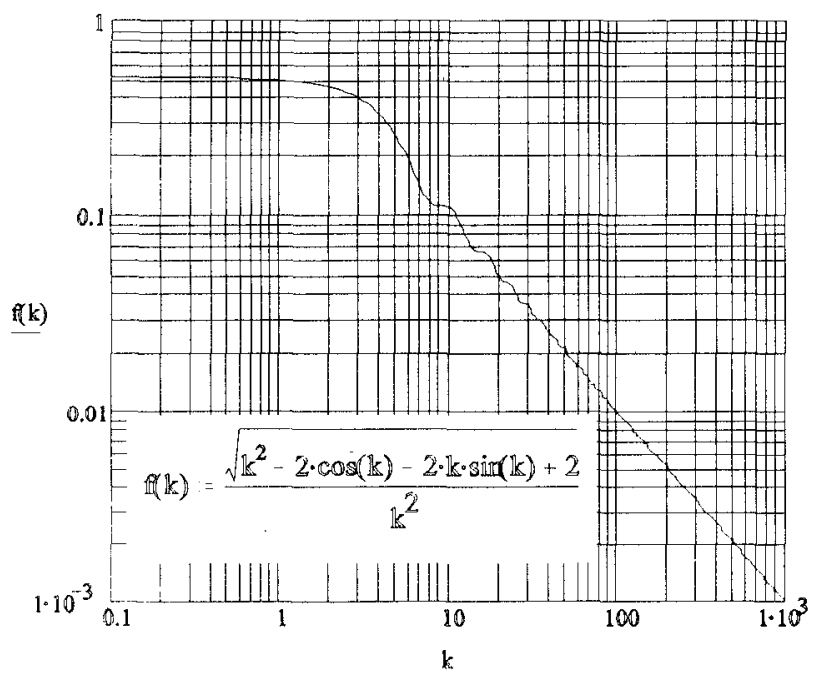

Fig. 5: Part of equation (3) as a function of $\mathrm{k}$.
The amplitude of the m'th harmonic of the discontinuous saw-tooth shown in figure 4 is:

$$
\begin{gathered}
A(m)=\frac{2 \cdot t_{\text {on }} \cdot \hat{I}_{L}}{T \cdot k^{2}} \cdot \sqrt{k^{2}-2 \cdot \cos (k)-2 \cdot k \cdot \sin (k)+2} \\
\text { where } k=m \cdot 2 \cdot \pi \cdot \frac{t_{\text {on }}}{T}
\end{gathered}
$$

Inserting some of the previous formulas yields:

$A(m)=\frac{4 \cdot \widehat{I}_{\text {mains }}}{k^{2}} \cdot \sqrt{k^{2}-2 \cdot \cos (k)-2 \cdot k \cdot \sin (k)+2}$

From figure 5 it can be seen that get the lowest noise current (i.e. lowest $\mathrm{A}(\mathrm{m})$ ) $\mathrm{k}$ must be as large as possible. This means that the on-time $t_{\text {on }}$ must be as large as possible. From (1) it can be seen that then the inductance $L$ must be as large as possible in order to get the lowest noise current.

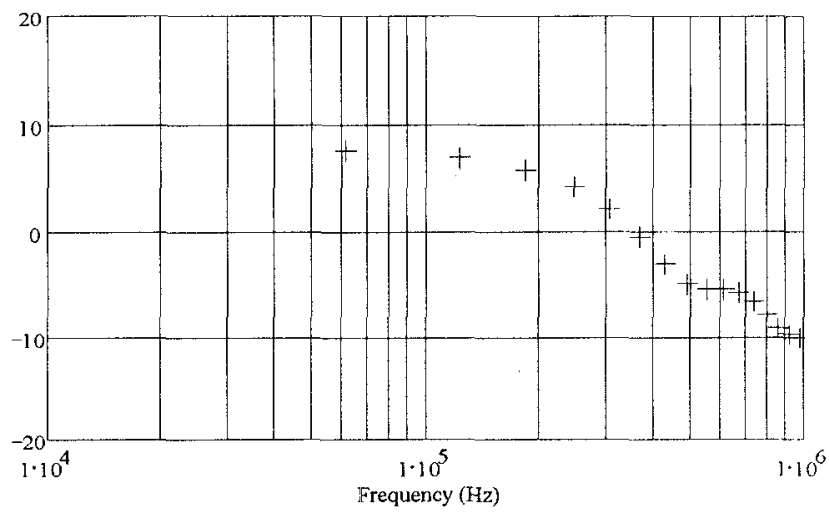

Fig. 6: Frequency spectrum in $\mathrm{dB}$ Ampere of $\mathrm{A}(\mathrm{m})$, the discontinuous saw-tooth wave-form.

\section{PFC flyback comparison.}

A comparison of figure 3 and 6 shows that they match exactly. Intuitively it must be so because the flyback input current of figure 2 is just a multiplication of a mains frequency sinus with amplitude 1 and the spectrum of the discontinuous saw-tooth waveform with amplitude $\hat{\mathrm{I}}_{\mathrm{L}}$ (assuming that the switching frequency much higher than mains frequency). This is an amplitude modulation. Bandpass filtering ( $9 \mathrm{kHz} \mathrm{BW}$ contains $+/-90$ side-bands of $50 \mathrm{~Hz}$ ) this spectrum followed by a peak detection reveals the amplitude of each of the harmonics of the switching frequency in the spectrum of the discontinuous saw-tooth waveform

\section{PFC flyback measurements.}

A PFC flyback $200 \mathrm{~W}, 230 \mathrm{~V} \mathrm{AC}, \mathrm{f}_{\mathrm{s}}=62.5 \mathrm{kHz}$ with $\mathrm{L}=48 \mathrm{uH}$ was built and tested. The peak input current frequency spectrum on figure 7 was measured. On figure 8 a prediction of the same spectrum is shown. 


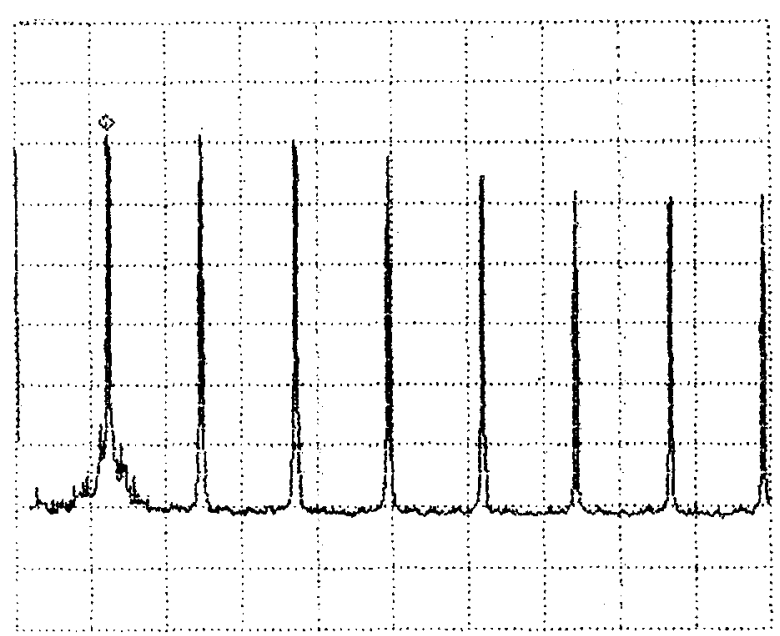

Fig. 7: Measured frequency spectrum. Horizontal:

Frequency, linear scale, $50 \mathrm{kHz} /$ div from $0 \mathrm{~Hz}$ to $500 \mathrm{kHz}$. Vertical: Peak current, $10 \mathrm{~dB} / \mathrm{div}$, top $=21 \mathrm{dBAmpere}=11.2 \mathrm{~A}$, bottom $=-79 \mathrm{dBAmpere}=112 \mathrm{uA}$.

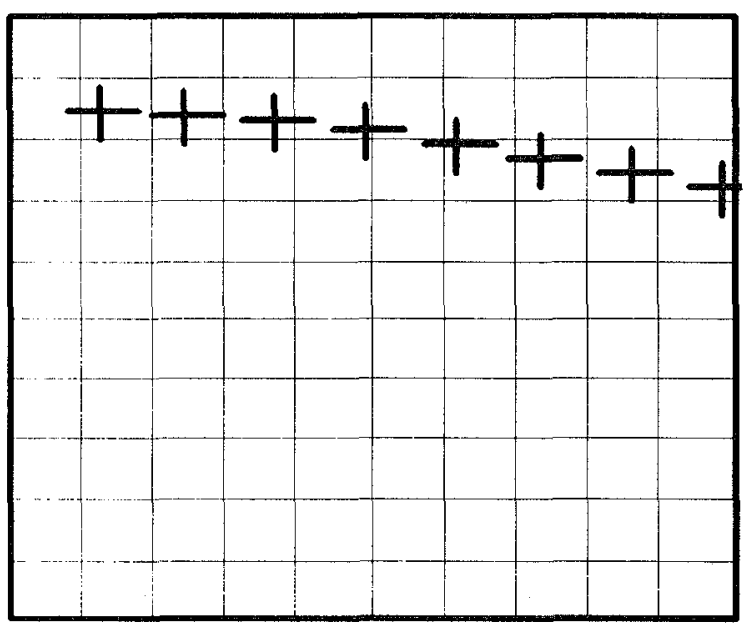

Fig. 8: Predicted frequency spectrum.

Horizontal: Frequency, linear scale, $50 \mathrm{kHz} / \mathrm{div}$ from $\mathrm{OHz}$ to $500 \mathrm{kHz}$.

Vertical: Peak current, $10 \mathrm{~dB} / \mathrm{div}$, top $=21 \mathrm{dBAmpere}=11.2 \mathrm{~A}$, bottom $=-79 \mathrm{dBAmpere}=112 \mathrm{uA}$.

This measurement in figure 7 shows good agreement with the predicted spectrum in figure 8 for all the harmonics, the $3^{\text {rd }}$ to $7^{\text {th }}$ harmonics are about $2 \mathrm{~dB}$ lower on the measurements compared to the prediction.

\section{E. Ainimum size core for the flyback inductor.}

It can be shown that the upper limit on the inductance when operation in discontinuous mode occurs at the lowest mains voltage and lowest $\mathrm{N}_{12}$ and it is:
$\mathrm{L}_{\max }=\frac{\left(\mathrm{U}_{0} \cdot \mathrm{N}_{12} \cdot \hat{\mathrm{U}}_{\text {in min }}\right)^{2}}{4 \cdot \mathrm{f}_{\mathrm{s}} \cdot \mathrm{P} \cdot\left(\mathrm{U}_{0} \cdot \mathrm{N}_{12}+\hat{U}_{\text {in min }}\right)^{2}}$ where $\mathrm{N}_{12}=\frac{\mathrm{N}_{1}}{\mathrm{~N}_{2}}$

For a given core to be used and not exceeding the maximum flux density it must have a permeanse of:

$A_{1} \leq \frac{f_{s} \cdot\left(\hat{B} \cdot A_{j}\right)^{2}}{4 \cdot P_{\max }}$ where $L=N_{1}{ }^{2} \cdot A_{1}$

where $\hat{B}$ is the maximum flux density of the core material and $A_{j}$ is the cross section area of the core. This means that there exists a minimum size ferrite core fulfilling the above demand. The inductance can be chosen more freely (only limited by the losses in the converter and core), but choosing it as large as possible gives the lowest noise currents.

\section{PFC BOOST OPERATING IN CONTINUOUS CONDUCTION MODE WITH AVERAGE CURRENT MODE CONTROL.}

The boost converter is very popular because it easily handles very high power. When operating a boost converter in continuous conduction mode with average current mode control the average of the input current becomes proportional to the input voltage.

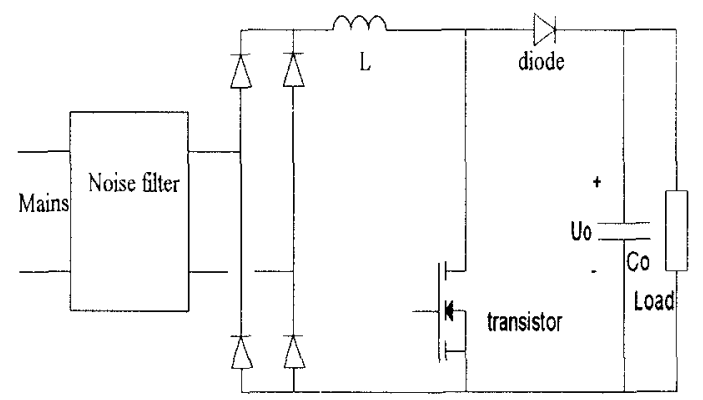

Fig. 9: Boost converter for PFC with input noise filter.

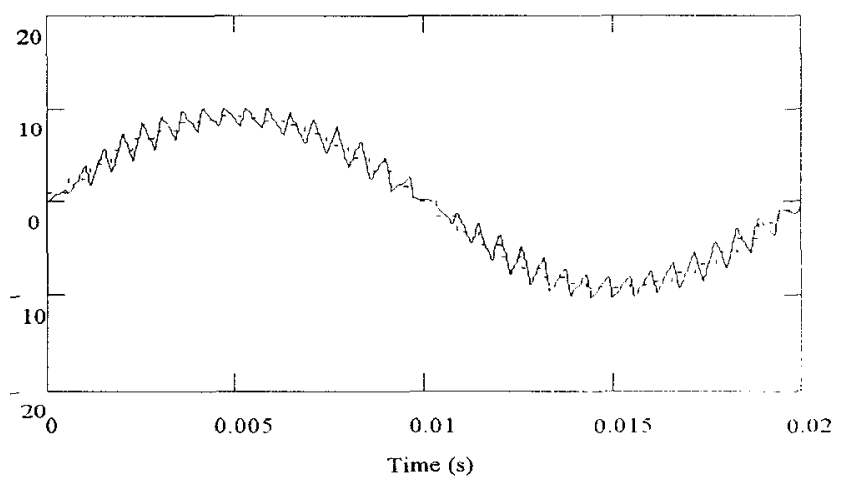

Fig. 10. Mains current and boost input current (in A) during one mains period (with a low ratio between switching and mains frequency to get a nice drawing).

And we have that: 


$$
\mathrm{D}=\mathrm{l}-\frac{\mathrm{u}_{\text {mains }}(\mathrm{t})}{\mathrm{U}_{\mathrm{o}}} \Leftrightarrow \mathrm{u}_{\text {mains }}(\mathrm{t})=(1-D) \cdot \mathrm{U}_{\mathrm{o}}
$$

where $D$ is the duty-cycle, and $u_{\text {mains }}$ is the mains voltage within one switching period (the switching frequency is assumed much higher than the mains frequency, then $u_{\text {mains }}$ can be assumed constant within one switching period).

\section{A. PFC boost input current FFT spectrum.}

A $1.5 \mathrm{~kW} 230 \mathrm{~V} \mathrm{AC}$ input and $\mathrm{U}_{\mathrm{o}}=400 \mathrm{~V}$ output PFC boost converter with a switching frequency of $140 \mathrm{kHz}$ and $\mathrm{L}=189 \mathrm{uH}$ has been simulated. The boost converter has a rather low ripple current on the input as shown on figure 10 . By applying FFT on the ripple current the spectrum on figure 11 can be computed [7].

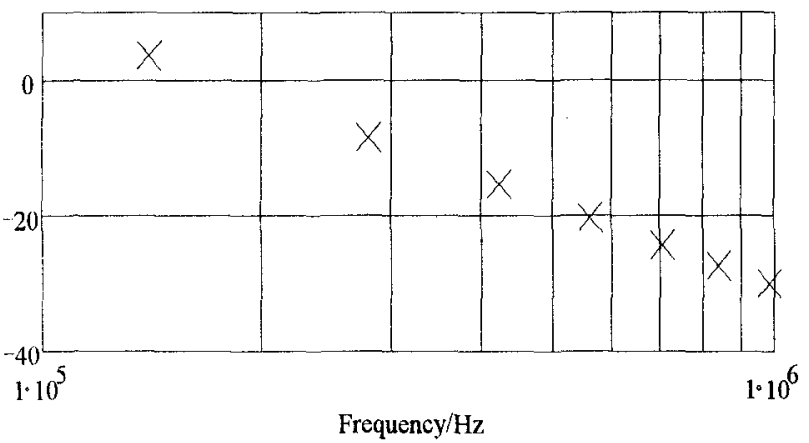

Fig. 11. Frequency spectrum of boost input current (in $\mathrm{dB}$ Ampere peak). Each of the points are harmonics of the switching frequency $f_{s}=140 \mathrm{kHz}$.

This FFT calculation takes a lot of time to get an exact result so a faster method is needed.

\section{B. Prediction of PFC boost input current spectrum.}

Looking at figure 10 we see that the waveform within one switching period consists of a sum of a switching ripple on top of the one switching period average of the mains current.

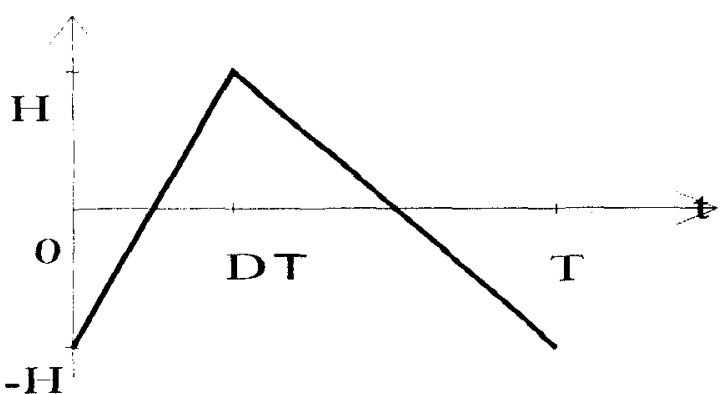

Fig. 12: Continuous triangle wave-form.
Removing the mains frequency current component we get the switching period ripple component on figure 12 where both the duty-cycle $D$ and the amplitude $H$ varies along the mains frequency period.

The amplitude of the m'th harmonic of the continuous triangle waveform shown in figure 12 is:

$A(m)=\frac{2 \cdot H \cdot|\sin (\pi \cdot m \cdot D)|}{\pi^{2} \cdot m^{2} \cdot D \cdot(1-D)}$

Inserting:

$\mathrm{u}_{\text {mains }}=\mathrm{L} \cdot \frac{\mathrm{dI}}{\mathrm{D} \cdot \mathrm{T}}=\mathrm{L} \cdot \frac{2 \cdot \mathrm{H}}{\mathrm{D} \cdot \mathrm{T}}$

into the spectrum $A(m)$ together with the duty-cycle formula yields:

$A(m)=\frac{U_{o} \cdot T \cdot|\sin (\pi \cdot m \cdot D)|}{\pi^{2} \cdot m^{2} \cdot L} \leq \frac{U_{0} \cdot T}{\pi^{2} \cdot m^{2} \cdot L}$

assuming the worst-case we have:

$\mathrm{A}(\mathrm{m}) \approx \frac{\mathrm{U}_{0} \cdot \mathrm{T}}{\pi^{2} \cdot \mathrm{m}^{2} \cdot \mathrm{L}}$

Figure 13 shows (10) graphical.

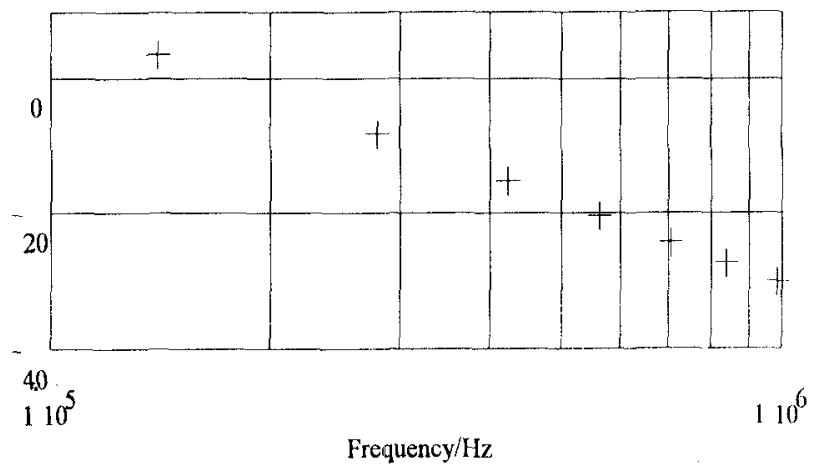

Fig. 13: Frequency spectrum in dB Ampere of $A(m)$ of the continuous triangle wave-form.

\section{PFC boost comparison.}

A comparison of figure 11 and 13 shows that they match exactly. Intuitively it is more difficult to explain this because the boost input current of figure 10 is a function of both the mains and the output voltage. But eventually the mains voltage cancels out and the spectrum is only dependant on the output voltage, the inductance, and the switching period. The spectrum is not dependant on the input power level as long as the boost converter operates in continuous conduction mode, at some low power level the boost converter goes into discontinuous conduction mode and then the spectrum becomes dependant on the input power, but this will be the subject in another paper. 


\section{PFC boost measurements.}

A PFC boost $1.5 \mathrm{~kW}, 230 \mathrm{~V}$ AC input and $400 \mathrm{~V}$ output, $\mathrm{f}_{\mathrm{s}}=140 \mathrm{kHz}$ with $\mathrm{L}=189 \mathrm{uH}$ was built and tested. Figure 14 shows the measured input current frequency spectrum.

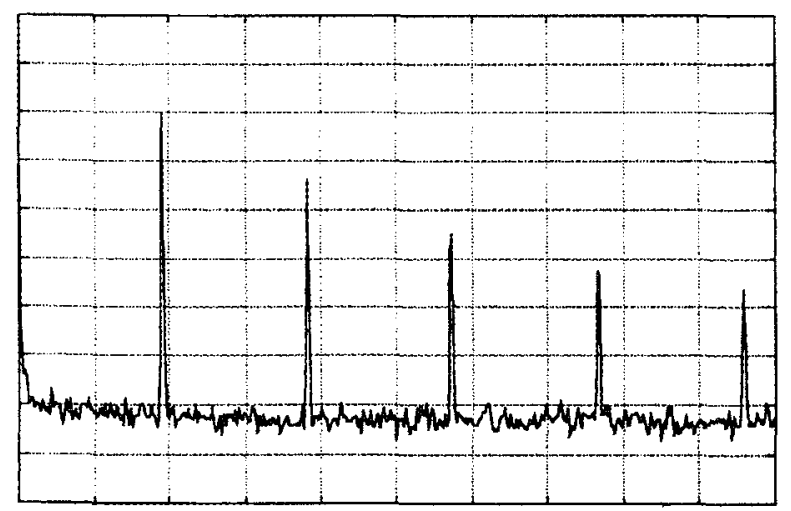

Fig. 14: Measured frequency spectrum. Horizontal:

Frequency, linear scale, $75 \mathrm{kHz} / \mathrm{div}$ from $0 \mathrm{~Hz}$ to $750 \mathrm{kHz}$. Vertical: Peak current, $10 \mathrm{~dB} / \mathrm{div}$, top $=24 \mathrm{dBAmpere}=15.8 \mathrm{~A}$, bottom $=-76 \mathrm{dBAmpere}=158 \mathrm{uA}$.

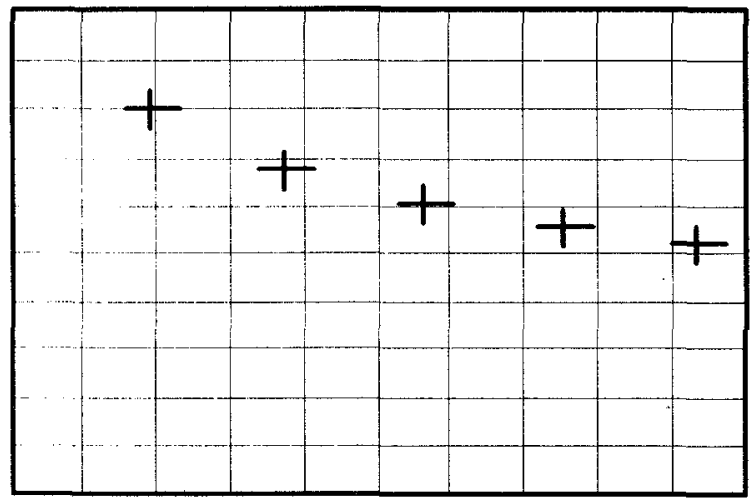

Fig. 15: Predicted frequency spectrum. Horizontal:

Frequency, linear scale, $75 \mathrm{kHz} / \mathrm{div}$ from $0 \mathrm{~Hz}$ to $750 \mathrm{kHz}$

Vertical: Peak current, $10 \mathrm{~dB} / \mathrm{div}$, top $=24 \mathrm{dBAmpere}=15.8 \mathrm{~A}$, bottom $=-76 \mathrm{dBAmpere}=158 \mathrm{uA}$.

This measurement shows good agreement with the predicted spectrum in figure 15 for the first and second harmonics, the $3^{\text {rd }}$ to $5^{\text {th }}$ harmonics are about $5 \mathrm{~dB}$ lower on the measurements compared to the prediction.

\section{DIFIIRENTIAL MODE NOISE INPUT FILTER REQUIREMENTS, A FIYBACK EXAMPLE}

Thus both the flyback and the boost converters can be seen as noise current sources from the input filter. This noise must be damped enough so that the noise voltage measured across a LISN impedance on the mains side of the input filter meets the conducted noise specifications

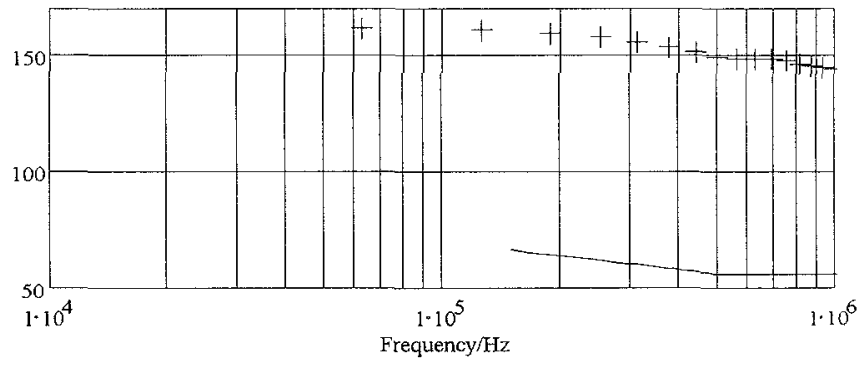

Fig. 16: Differential mode noise (in $\mathrm{dBuV}$ ) on top and (quasi) peak noise voltage limit (EN55022 class B [6]) on bottom for the flyback converter example without input noise filter (e.g. measured across one of the two LISN impedance's).

From figure 16 it can be seen that the $3^{\text {rd }}$ harmonic and higher should be damped at least $95 \mathrm{~dB}$ by the input differential mode noise filter to get below the limit. This could be done using any of the methods in $[3,4,5]$.

\section{REMARKS}

This is differential mode noise. Maybe in a similar way the common mode noise could be analysed and simple predictions found, in order to design a common mode filter.

\section{CONCLUSION}

Two new and simple methods to make predictions of the differential mode input filter requirements are presented, one for flyback and one for boost unity power factor converters. It is shown that these two methods match very well with very complex and time consuming simulations. And the methods have been verified by measurements on experimental prototypes. This gives the designer a fast method to predict the differential mode input noise filter requirements early in the design phase of unity power factor converters. These methods can act as tools for designing minimum size input filters and power factor converters.

\section{REFERENCES}

[1]: M. Albach: "Conducted Interference Voltage of AC-DC Converters." PESC' 86 p. 203-212.

[2]: M. Albach: "High frequency Interferences Standards, Problems and Solutions." Philips Research Laboratory. $47 \mathrm{pp}$

[3]: Anatol I. Zverev: Handbook of Filter Synthesis. Wiley 1967. ISBN (1-47198680-1

[4]: F. Shih, D. Y. Chen, Y. Wu, and Y. Chen: "A Procedure for Designing EMI Filters for AC Line Applications." IEEE Tran. on Power Elec. Vol. 11, No. 1, January 1996, p.170-181.

[5]: V. Vlatkovi' ', D. Borojevi'c, and F. C. Lee: "Input Filter design for Power Factor Correction Circuits." IEEE Tran. on Power Eles. Vol. 11. No. 1, January 1996, p. 199-205.

[6]: CISPR22 and EN55022 class B.

[7]: Christian Wolf: Ensrettere med sinusformet netstrom. Ph.d.-dissertation (in Danish). IAU DTU 1995. 